\title{
CHOICE OF THE OPTIMAL CONTROL STRATEGY FOR THE DUPLEX-PROCESS OF INDUCTION MELTING OF CONSTRUCTIONAL IRON
}

\author{
Iegor Dymko \\ National Technical University «Kharkiv Polytechnic Institute» \\ 21 Kirpichova str., Kharkiv, Ukraine, 61002 \\ litvo11@kpi.kharkov.ua
}

\begin{abstract}
To find effective control of the duplex process of induction melting in conditions of uncertainties, a method was suggested that made it possible to obtain optimal controls for both stages: melting and thermal treatment.

It is shown how the search for an optimal melting control strategy can be performed using the theory of statistical games. At the same time, it is selected which of the melting regimes will be the best with the existing provision of the shop with charge materials. The costs of melting are the total costs, consisting of:

- costs for the selected technological mode of melting (including costs for materials);

- costs from the potential rejection of castings due to the non-conformity of the chemical composition of the alloy to the specified - due to the incorrectly chosen melting mode;

- costs from the downtime due to the fact that the necessary amount of metal from the furnace is not delivered to the conveyor.

The choice of an optimal control strategy in accordance with the proposed procedure can remove uncertainty in the evaluation of input process variables if they are taken as indicators of the charge quality.

To find the optimal control at the stage of the heat treatment, a multialternative description of the final state is proposed on the basis of solving the problem of ridge analysis. This makes it possible to remove the uncertainty in the estimation of the final state, which allows a lot of optimal solutions in the sense of achieving a given quality. It is shown that such approach makes it possible not only to synthesize the optimal controller of the temperature regime on the basis of an analysis of the system of differential equations describing the control object, but also the application of the Pontryagin maximum principle to search for optimal control of the thermal treatment.

The proposed method allows to determine the optimal control in the sense of stabilization for a given process parameter of the duplex process of induction melting. The resulting solutions form the necessary logical conditions for the logic control unit for the control system of the duplex induction melting process.
\end{abstract}

Keywords: optimal control strategy, duplex induction melting process, multialternative description of the final state.

\section{Introduction}

The processes of melting control are complex for formalization, since their modeling in the melting of alloys of different grades of cast iron involves the need to take into account a large number of factors heterogeneous in terms of physical principles. Some of them can't be precisely controlled in a real-time process. Therefore, an accurate assessment of the state of the system for choosing optimal control is often not possible. Elimination of these difficulties is probably possible with the implementation of alternative options: either by laying the appropriate technical solutions at the design stage of induction melting complexes, or by developing optimal control algorithms directly for the operation phase of furnaces in the shops of enterprises. The latter can be considered more appropriate, since the choice of optimal control algorithms is a more flexible solution. Consequently, an adequate mathematical description and synthesis on its basis of optimal control are relevant.

\section{Analysis of published data and problem definition}

Attention is drawn to the fact that many sources devoted to the control of induction melting processes illuminate only the "electric power" component in the induction melting 
control system [1-5]. Such one-sided coverage of the problem associated with the melting control can't be considered satisfactory and is of practical interest for specialists in the field of power electronics than for technologists and specialists in the field of automation of induction melting. A technological parameter that "links" the electric power and technological components, one can recognize the mixing of the melt in the crucible of the induction furnace, caused by the action of electrodynamic forces, and this fact was noted, in particular, in work [6]. It should be especially noted that this process is more important for the melt aging and overheating stage than for the melting stage of the lump charge, as, for example, described in [6]. It is the period of melting, when the furnace works as a mixer, all the necessary oxidation-reduction processes must be fully realized. Often, such induction furnaces are induction channel mixers. The source of power for all such furnaces is an electric furnace transformer, and for crucible mixers - an electric transformer or a static thyristor frequency converter. The latter are just used as power sources for crucible mixers, although the transition to them for medium frequencies is usually not required because of the already high values of the relative size of the charge [7]. From this it follows that the priority is the use of thyristor converters as key elements of control systems. The implementation of such control is possible in induction furnaces with thyristor converters, in which control is controlled by the magnitude and phase shift of the currents of the middle frequency flowing in them. At the same time, the main technological factor on which the efficiency of the melting process depends in terms of stabilizing the chemical composition and temperature of the alloy is its mixing due to the action of electrodynamic forces. However, the chemical composition and the temperature on which it depends are available for measurement in the industrial process. And temperature measurement can also be difficult. If talk about the duplex process of induction melting, then uncertainty arises both at the first stage - melting, because of the complexity of quality control of the charge to be loaded, and on the second - because of an ambiguous evaluation of the quality of the alloy obtained. The latter is due to the fact that the marking of cast iron in accordance with the standards takes into account only the mechanical properties, which in a complex way depends on the chemical composition of the cast iron. The multidimensionality of such dependence admits a set of solutions, among which a subset of optimal solutions.

Therefore, in order to find effective control of induction melting, it is necessary to develop a method that would allow to obtain optimal controls for both stages of the duplex process under the conditions of these uncertainties.

\section{Materials and Methods}

The study was conducted in the foundry of the private joint-stock company "Kremenchuk plant of road machines" (Ukraine). The technological scheme of the process includes melting of cast iron in three induction furnaces with acid lining ИCT1-0.8M5 with a capacity of 1 ton and subsequent thermo-time treatment with an induction crucible mixer ИЧТ6/1.6-И8 with a capacity of 6 tons. The thermo-time treatment of the melt in the ИЧТ-6/1.6-И8 is designed for soaking at a given temperature and bringing the melt chemical composition to the specified temperature. When a request is received from the conveyor for a predetermined amount of the melt, a corresponding portion of melt is dispensed into the ladle, which is transported to the mold pouring station.

The algorithm of the technological process and the implementation of the principles of controlling the duplex process of induction melting are given in [8].

Table 1 shows a sample fragment of experimental data representing the results of chemical analysis of the alloy during the melting process and the results of determining the tensile strength as the main output parameter of the quality of melting. The total sample consisted of $\mathrm{N}=200$ results of serial fusions.

The obtained data describe the actual parameters of the melting process with the selected control option. 
Table 1

Fragment of sample of experimental industrial data

\begin{tabular}{|c|c|c|c|c|}
\hline $\mathrm{C}, \%$ & Ceq, \% & $\mathrm{Cr}, \%$ & $\mathrm{Cu}, \%$ & TS, MPa \\
\hline 3,63 & 4,387 & 0,32 & 0,19 & 190 \\
\hline 3,57 & 4,282 & 0,3 & 0,15 & 190 \\
\hline 3,58 & 4,323 & 0,42 & 0,21 & 190 \\
\hline 3,57 & 4,284 & 0,32 & 0,12 & 180 \\
\hline . & . & . & . & . \\
\hline 3,6 & 4,36 & 0,28 & 0,13 & 200 \\
\hline 3,52 & 4,319 & 0,35 & 0,21 & 200 \\
\hline 3,47 & 4,2 & 0,3 & 0,26 & 200 \\
\hline 3,56 & 4,224 & 0,29 & 0,18 & 200 \\
\hline 3,68 & 4,447 & 0,37 & 0,18 & 200 \\
\hline 3,67 & 4,373 & 0,26 & 0,19 & 200 \\
\hline 3,57 & 4,358 & 0,32 & 0,16 & 200 \\
\hline . & . & . & . & . \\
\hline 3,15 & 3,896 & 0,33 & 0,3 & 300 \\
\hline
\end{tabular}

\section{Results}

\section{1. Selection of the optimal control strategy at the melting stage in the induction fur- nace ИСТ1/0.8-М5}

To select the optimal control strategy by priority criteria, the methods of the theory of statistical games are used [9]. The whole set of states of nature $\vartheta$ in which the operator or the control system has to make decisions is designated as $\theta=\left(\vartheta_{1}, \ldots, \vartheta_{m}\right)$. The a priori distribution of probabilities $\xi(\vartheta)$ on the space of states of nature $\Theta$ is obtained on the basis of statistical data on the results of melting in different modes:

- mode No. $1\left(a_{1}\right)$ - induction melting is carried out on a "swamp" in all three furnaces, but the volume of the "swamp" is different;

- mode No. $2\left(\mathrm{a}_{2}\right)$ - induction melting is conducted in one or two furnaces on a solid charge, and in the remaining two furnaces (one oven) - on a "swamp";

- mode No. $3\left(\mathrm{a}_{3}\right)$ - induction melting is conducted in all three furnaces simultaneously on a solid charge.

The a priori probability distribution $\xi(\vartheta)$ is defined as a mixed strategy. The task is to accept the most acceptable solution from the set $\left(a_{1}, a_{2}, \ldots, a_{i}\right)$, and each of these actions is a pure strategy. To assess each of the possible actions, it is permissible that when performing an action a, there may be a loss associated with energy costs and no chemical composition falling within a given range, and estimated by the loss function $\mathrm{L}(\vartheta, \mathrm{a})$.

$$
\mathrm{Q}=\left[\mathrm{q}_{\mathrm{ij}}\right]
$$

where $\mathrm{q}_{\mathrm{ij}}=\mathrm{L}\left(\vartheta_{\mathrm{i}}, \mathrm{a}_{\mathrm{i}}\right)$.

If an a priori distribution of probabilities $\xi(\vartheta)$ is known on the state space of nature $\theta$, then the average losses resulting from the selected control can be calculated

$$
\mathrm{L}(\xi, \mathrm{a})=\sum_{v \in \theta} \mathrm{L}(v, \mathrm{a}) \xi(v)
$$

The best action is a Bayesian action $\mathrm{a}^{*}$, minimizing the probable loss

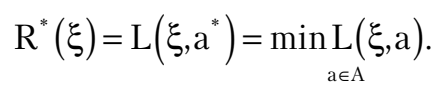

This takes into account the existence of an acceptable strategy $\eta(a)$ - this means that no strategy $\eta^{\prime}(a)$ can be found that is better than $\eta(a)$, i. e., there is no such strategy for which 
the losses in its implementation are less or equal than the losses in the implementation of the strategy $\eta(\mathrm{a})$ :

$$
\mathrm{L}\left(v, \eta^{\prime}\right) \leq \mathrm{L}(v, \eta)
$$

Admissible strategies can be defined on the lower border of the S-game:

$$
\mathrm{S}=\omega \mathrm{C}_{1}+(1-\omega) \mathrm{C}_{2}
$$

where $\omega$ varies in the range: $0 \leq \omega \leq 1, C_{1}, C_{2}, C_{3}$ specify the coordinates of points reflecting possible losses in the $\mathrm{S}$-game.

If for every outcome of the experiment $\mathrm{z} \in \mathrm{Z}$ a decision $\mathrm{a}=\mathrm{d}(\mathrm{z})$ is chosen, then for this outcome $\vartheta \in \theta$ there will be a corresponding loss

$$
\mathrm{L}(\mathrm{v}, \mathrm{a})=\mathrm{L}[\mathrm{v}, \mathrm{d}(\mathrm{z})]=\mathrm{L}_{\mathrm{z}}(\mathrm{v}, \mathrm{d})
$$

The average loss (risk function) can be determined from relation

$$
\rho(v, d)=\sum_{z} L_{z}(v, d) \rho_{v}(z)
$$

To select mixed strategies, it is necessary to use the random selection mechanism that determines the probability distribution $\eta(d)$ on the space D. The risk function $\rho(\vartheta, \eta)$ when applying a mixed strategy $\eta(d)$ can be obtained by averaging $\rho(\vartheta, d)$ over all the pure strategies included in this mixed strategy:

$$
\rho(v, \eta)=\sum_{d} \rho(v, d) \eta(d)
$$

or taking into account (7)

$$
\rho(v, \eta)=\sum_{z, d} L_{z}(v, d) \rho_{v}(z) \eta(d)
$$

The essence of minimax in choosing the optimal melting mode in this case is choosing a strategy $\eta(d)$ in which the average risk $\rho(\vartheta, \eta)$ with the worst impact of external factors would be minimal. Thus, the choice of the minimax strategy $\eta *$ is obtained from the condition

$$
\rho\left(v, \eta^{*}\right)=\min _{\eta} \max _{v} \rho(v, \eta)
$$

If to use the notion of expected risk $\rho(\vartheta, \eta)$ - average risk, taking into account the impact of all uncontrolled external factors $\vartheta \in \theta$ and the a priori probability distribution in space $\theta$ - it will be

$$
\rho(\xi, d)=\sum_{\vartheta} \rho(v, d) \xi(v)
$$

At the same Bayesian principle requires the use of such a decision function $\mathrm{d}^{*}$, at which the expected risk will be minimal [9]:

$$
\rho^{*}(\xi)=\rho\left(\xi, d^{*}\right)=\min _{\xi} \rho(\xi, d) .
$$

It is required to determine the optimal melting strategy, i. e., to choose which of the melting regimes will be best with the existing provision of the shop with charge materials. The costs of melting are the total costs, consisting of: 
- costs for the selected technological mode of melting (including costs for materials);

- costs from the potential rejection of castings due to the non-conformity of the chemical composition of the alloy to the specified - due to the incorrectly chosen melting mode;

- costs from the downtime due to the fact that the necessary amount of metal from the furnace is not delivered to the conveyor.

To apply the described principles of choosing the optimal strategy, it is necessary to use as input data the costs recalculated in the percentage of losses that the enterprise carries with the chosen melting mode. This value for various melting modes, depending on the quality of the charge, is obtained by averaging the indices of industrial melting and expert estimates (Table 2). In Table 2, the following designations have been adopted: $\mathrm{v}_{1}$ - charge qualitative (according to the "heredity" of materials), $v_{2}$ - charge poor-quality (according to the "heredity" of materials), $\xi(v)$ - a priori probabilities of states of nature (i.e., probabilities of low and high quality charge from the experience of melting at a given enterprise ), $a_{1}, a_{2}, a_{3}$ - modes of conducting melting depending on the quality of the input charge, $\mathrm{L}\left(\xi, \mathrm{a}_{\mathrm{i}}\right)$ - the percentage of losses in the selected melting mode.

Table 2

A priori probabilities of states of nature and losses in the problem of choosing the optimal melting strategy

\begin{tabular}{ccccc}
\hline & $\xi(\mathbf{v})$ & & $\mathbf{A}$ & \\
\cline { 3 - 5 } & & $\mathbf{a}_{1}$ & $\mathbf{a}_{2}$ & $\mathbf{a}_{3}$ \\
\hline $\mathrm{v}_{1}$ & 0,75 & 4 & 5 & 9 \\
$\mathrm{v}_{2}$ & 0,25 & 11 & 7 & 5
\end{tabular}

The game matrix in the form of an equivalent S-game is shown in Fig. 1.

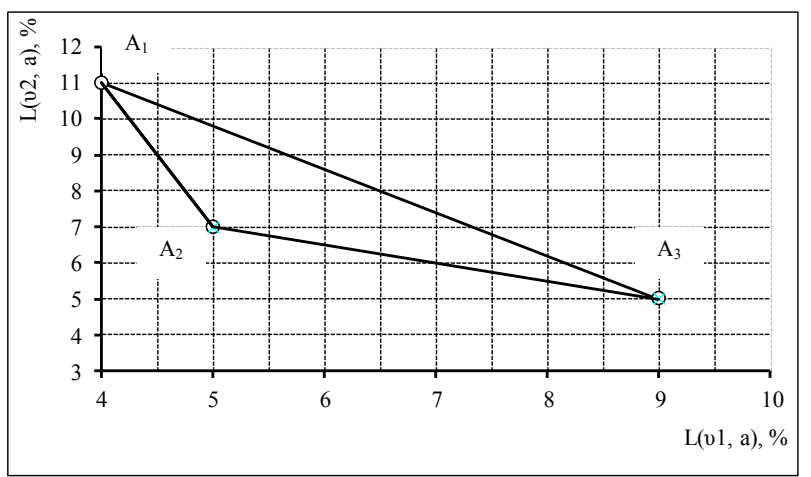

Fig. 1. An equivalent S-game in the problem of choosing admissible strategies

To determine the minimax strategy, the dependence $L(v, \eta)$ on the value $\omega, 0 \leq \omega \leq 1$ for both segments $A_{1} A_{2}$ and $A_{2} A_{3}$, described by the equations of the lower boundary of the $S$-game, is constructed:

- for segment $\mathrm{A}_{1} \mathrm{~A}_{2}$ :

$$
\begin{gathered}
4 \omega+5(1-\omega)=5-\omega \\
11 \omega+7(1-\omega)=7+4 \omega
\end{gathered}
$$

- for segment $\mathrm{A}_{2} \mathrm{~A}_{3}$ :

$$
\begin{aligned}
& 5 \omega+9(1-\omega)=9-4 \omega ; \\
& 7 \omega+5(1-\omega)=5+2 \omega .
\end{aligned}
$$


The minimum on the segment $A_{1} A_{2}$ is attained at $\omega=0$ and corresponds to $L(v, \eta)=7$, and the minimum on the segment $\mathrm{A}_{2} \mathrm{~A}_{3}$ is attained at $\omega=0.67$ and corresponds to $L(v, \eta)=6$, Consequently, the minimax principle gives an optimal mixed control strategy for melting $\eta^{*}=(0 ; 0,67 ; 0,33)$

\section{2. Search for optimal control at the melting stage}

Controlling the switching of the voltage stages of the transformer leads to a change in the temperature of the melt, which in turn leads to melting of the solid charge to the melting point, which depends on the chemical composition of the alloy (liquidus temperature). The mathematical model describing the process has the form [8].

$$
\dot{\mathrm{T}}=\mathrm{k}_{1} \mathrm{k}_{2} \mathrm{~N}
$$

where $\mathrm{k}_{1}$ is coefficient of proportionality, depending on the plant power and the value of reactive power compensation,

$$
\mathrm{k}_{2}=\left(\frac{\mathrm{dG}}{\mathrm{dT}}\right)^{-1}
$$

is the inverse of the melting rate.

To solve the problem of finding the optimal control, it is necessary to set the values of the coefficients $\mathrm{k}_{1}$ and $\mathrm{k}_{2}$.

It is known that the coefficient $\mathrm{k}_{1}$ is selected from the range of $0.8-0.9$ and for the ИСТ1/0.8-M5 furnace can be adopted 0.85 . That is, $\mathrm{k}_{1}=0.85$.

The value of the coefficient $\mathrm{k}_{2}$ can be determined from the technical characteristics of the furnace ИСТ1/0.8-M5 by determining the ratio of the melting rate to the temperature drop - from the initial temperature of the cold charge to the total melt temperature $\left(\mathrm{T}_{\text {liq }}+\mathrm{T}_{\mathrm{ov}}\right)$. Here $\mathrm{T}_{\text {liq }}$ is the liquidus temperature, $\mathrm{T}_{\text {ov }}$ is the temperature of the melt overheating above the liquidus temperature.

In view of this, $\mathrm{k}_{2}=0,915^{-1}=1,093$.

Therefore, the mathematical model for finding the optimal control takes the form

$$
\frac{\mathrm{dT}}{\mathrm{dt}}=0,92905 \mathrm{~N}
$$

The task of finding the optimal control is to determine the optimal control $u(t)$, which transfers the process in a minimum time from the given initial state $T^{(0)}$ to the finite $T^{(\mathrm{k})}$, if the range of possible values of the control action is limited by inequality $-\mathrm{U} \leq \mathrm{u} \leq \mathrm{U}$. This formulation of the problem makes it possible to apply the Pontryagin maximum principle to search for optimal control. As a result, the optimal control law is obtained in the form (15) and the optimal phase trajectories in the form (16):

$$
\begin{gathered}
\mathrm{u}_{\mathrm{opt}}=\mathrm{U} \operatorname{sgn}\left(\mathrm{T}^{(\mathrm{k})}-\mathrm{T}^{(0)}\right) ; \\
\mathrm{T}^{(\mathrm{k})}=\left[\mathrm{U} \operatorname{sgn}\left(\mathrm{T}^{(\mathrm{k})}-\mathrm{T}^{(0)}\right)\right] \mathrm{t}+\mathrm{T}^{(0)} .
\end{gathered}
$$

Positive control leads to an increase in the input power, as a result of which the temperature increases linearly. In this case, the time to reach the set temperature $\left(\mathrm{T}_{\text {liq }}+\mathrm{T}_{\mathrm{ov}}\right)$ has the form

$$
\mathrm{t}^{(\mathrm{k})}=\frac{\left|\mathrm{T}^{(\mathrm{k})}-\mathrm{T}^{(0)}\right|}{\mathrm{U}} .
$$

Negative control is necessary only in the case when the temperature of the melt must be reduced. And this can happen when the melt is overheated above the required level. 
Melting on the "swamp" makes it possible to use the heat of the melt remaining in the furnace to increase the melting rate of the charge, the solid pieces of which are loaded into the hot bath. This means that the initial temperature $\mathrm{T}^{(0)}$ is large in absolute value, and the correction for the initial state, taking into account the equations describing the decrease in the melt temperature due to the addition of the weight of the charge $g_{t},(\Delta T)[8]$, can be calculated as follows:

- at $\mathrm{T}>\mathrm{T}_{\mathrm{m}}$

$$
\mathrm{T}^{(\mathrm{k})}=\left[\mathrm{U} \operatorname{sgn}\left(\mathrm{T}^{(\mathrm{k})}-\mathrm{T}^{(0)}\right)\right] \mathrm{t}+\left(\mathrm{T}^{(0)}+\frac{\mathrm{g}_{\mathrm{t}}}{\mathrm{G}_{\mathrm{t}}} \frac{\mathrm{c}_{\mathrm{s}}+\mathrm{cT}}{\mathrm{c}}\right),
$$

- at $\mathrm{T}=\mathrm{T}_{\mathrm{m}}$

$$
\mathrm{T}^{(\mathrm{k})}=\left[\mathrm{Usgn}\left(\mathrm{T}^{(\mathrm{k})}-\mathrm{T}^{(0)}\right)\right] \mathrm{t}+\left(\mathrm{T}^{(0)}+\left(\frac{\mathrm{g}_{\mathrm{t}}}{\mathrm{G}_{\mathrm{t}}}-\frac{\mathrm{c}_{\mathrm{s}}}{\mathrm{cT}+\mathrm{c}_{\mathrm{s}}}\right)\left(\frac{\mathrm{cT}+\mathrm{c}_{\mathrm{s}}}{\mathrm{c}}\right)\right) .
$$

It follows from Eqs. (18) and (19) that the loading of the cold charge into the "swamp" makes it possible to increase the melting rate, which is reflected in the coefficient $\mathrm{k}_{2}$. Its value thus increases and, as a consequence, the tangent of the slope of the phase trajectory (16) changes.

\section{3. Synthesis of the optimal controller of the temperature regime of the induction mixer on the basis of a multialternative description of the final state}

To synthesize the optimal temperature controller in an induction mixer, one can apply a method which theory is described in [10]. According to it, the phase trajectory of the system when choosing a system of differential equations (SDE), describing the change in the chemical composition over time, with a change in the melt temperature, as a mathematical model, intersects the admissible region at two points. If the content of carbon $(\mathrm{C}, \%)$ and the carbon equivalent $\left(\mathrm{C}_{\mathrm{eq}}, \%\right)$ are chosen as the phase variables, with the constancy of the remaining elements of the chemical composition (Table 1), then the boundaries of the permissible region can be formed by a functional dependence of the form $\mathrm{C}=\mathrm{f}\left(\mathrm{C}_{\mathrm{eq}}\right)$. Moreover, the lower limit corresponds to the combinations $\left(\mathrm{C}, \mathrm{C}_{\mathrm{eq}}\right)$, which provides the given parameters of the quality of cast iron, and the upper one - to the combinations at which the crucible reaction begins to develop. Analytically, these boundaries can be described using the methods of parametric classification [11]. With this in mind, the problem of synthesizing an optimal temperature controller can be formulated as follows: in the shortest time, transfer the system from the initial state described by the coordinate $\left(\mathrm{C}^{(0)} ; \mathrm{C}_{\mathrm{eq}}{ }^{(0)}\right)$ at a given moment of the technological process, to the final one, described by the equation of the final state $\left(\mathrm{C}^{(\mathrm{T})} ; \mathrm{C}_{\text {eq }}{ }^{(\mathrm{T})}\right)$. In this case, the final state is chosen from the condition for solving the optimization problem for the mathematical model "composition-property". Such dependencies can be obtained on the basis of the application of the procedure of artificial orthogonalization from the data of a passive experiment [12-14]. The final state, according to [10], is a description of the solution of the problem of comb analysis.

Based on the experimental industrial data (Table 1), using the artificial orthogonalization method, a regression equation of the form $\mathrm{TS}=\mathrm{f}\left(\mathrm{C}, \mathrm{C}_{\mathrm{eq}}\right)$ was obtained, where TS is the tensile strength of pig iron, MPa (Table 1). On the basis of this equation, a parametric description of the ridge analysis procedure is performed, which makes it possible to investigate the response surface in a stationary region and perform a multialternative description of the final state (Fig. 2).

Each of the set of suboptimal values for the quotient space $(\mathrm{N} \times 2)$ is a curve of the form $\mathrm{x}_{1}=\mathrm{f}\left(\mathrm{x}_{2}\right)$, describing the set of suboptimal values of the input variables that provide the given values of the output variable. In the notations used, $\mathrm{x}_{1}$ is the carbon content in cast iron $(\mathrm{C}, \%), \mathrm{x}_{2}$ is the carbon equivalent of cast iron $\left(\mathrm{C}_{\mathrm{eq}}, \%\right)$.

In other words, each of the descriptions of the final state, in fact, forms the requirements for the quality of cast iron. The multialternative final state thus formed requires the solution of the problem of choosing the one of which the optimum control should be sought. The initial data in this case is the actual initial state in which the mixing process is located. Depending on this, the control sign is selected. The essence of the principle is as follows. 


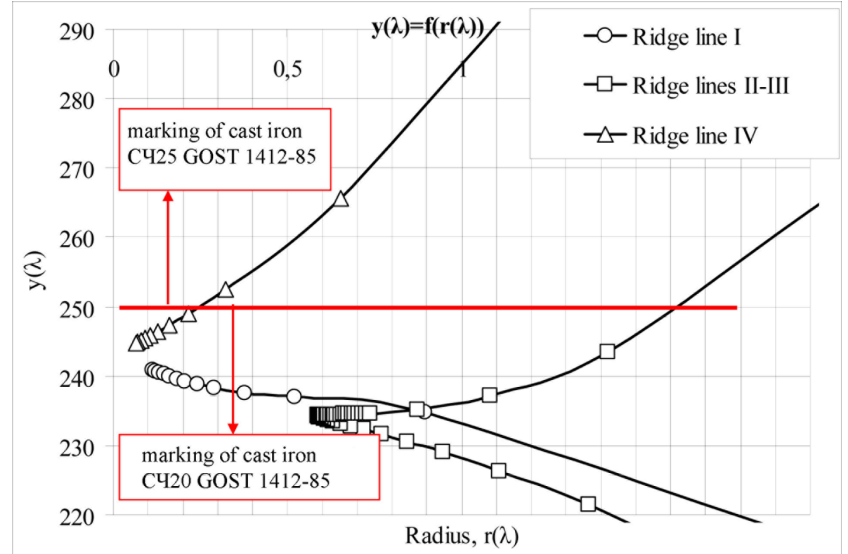

Fig. 2. Demonstration of the principle of a multialternative description of the final state as a set of suboptimal values of variables

As soon as the temperature reaches the upper permissible region, the control action (or control signal) of the corresponding sign is performed. This time $t_{s l}$, therefore, corresponds to the first switching, and the coordinates of the object at a given time correspond to the new initial state. In other words, if the previous initial state had the form $\left(\mathrm{x}_{1}(0), \mathrm{x}_{2}(0)\right)=\left(\mathrm{x}_{1}(\mathrm{i}-1), \mathrm{x}_{2}(\mathrm{i}-1)\right)$, then the new initial state, which the object falls into when the upper permissible region of the final state at time $t_{s l}$, has the form $\left(\mathrm{x}_{1}(0), \mathrm{x}_{2}(0)\right)=\left(\mathrm{x}_{1}(\mathrm{i}), \mathrm{x}_{2}(\mathrm{i})\right)$. As a result, the phase trajectory changes and the temperature begin to decrease, moving to its lower acceptable boundary. As soon as the temperature reaches it, the control action (or control signal) of the corresponding sign is again executed. The switching time moment corresponds to $t_{\mathrm{s} 2}$, and the intersection point of the phase trajectory and the lower permissible temperature boundary forms a new initial state $\left(\mathrm{x}_{1}(0), \mathrm{x}_{2}(0)\right)=\left(\mathrm{x}_{1}(\mathrm{i}+1), \mathrm{x}_{2}(\mathrm{i}+1)\right)$ and so on, until the system can be kept within a specified range $\pm \delta$ for a given time. The latter corresponds to the requirements of the technological process for the temperature regime in the induction mixer. Analytic description of the lower and upper boundaries, as already mentioned above, is a solution to the problem of parametric classification.

The described principle of constructing control is shown in Fig. 3.

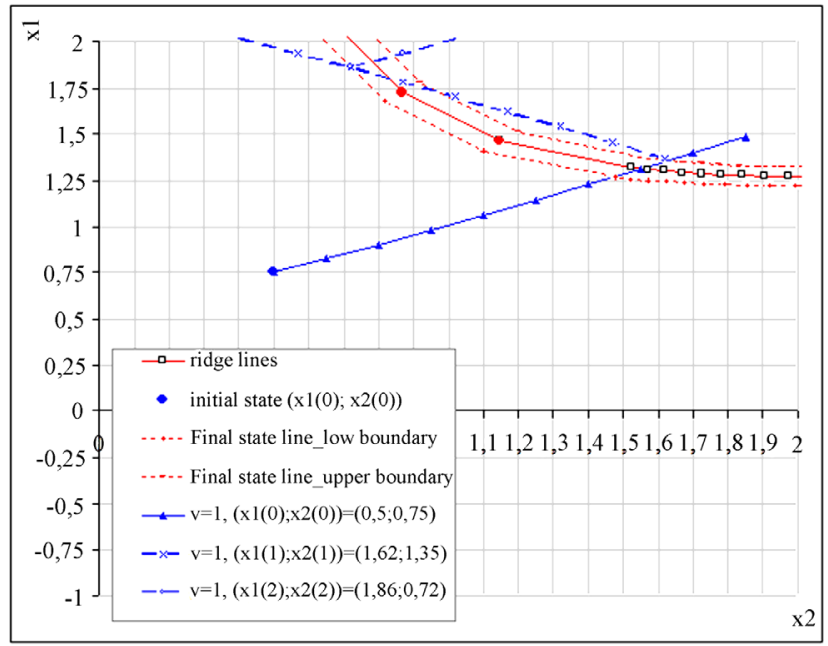

Fig. 3. The principle of control synthesis

As follows from the results of numerical simulation, in this control variant the system is always within the permissible range. This means that, regardless of the time at which the application for the melt is received, the temperature regime in the induction mixer will match the set one. The search for optimal control should be conducted relative to the nearest final state line. In this case, 
the distance from the phase space point corresponding to the initial state to the final state line is calculated as

$$
d_{i j}=\sqrt{\left(x_{1 j}-x_{10}\right)^{2}+\left(x_{2 j}-x_{20}\right)^{2}}
$$

where $x_{1 j}, x_{2 j}$ - the coordinates of the points on the line of the final state, $x_{10}, x_{20}-$ the coordinates of the point describing the initial state.

If the lines of the ridges describing the lines of the final state are not straight, such a stepby-step procedure is suggested.

Step 1. In the phase space, a triangle is formed, in which the vertices are the two extreme points of the final state line, for example, corresponding to the restrictions on the input variables, and the third vertex is the point describing the initial state. This procedure is performed for each of the alternative end state lines.

Step 2. Let's calculate the centers of gravity for each of the triangles obtained by formula

$$
x_{i c g}=\frac{1}{3} \sum_{j=1}^{3} x_{i j} .
$$

Step 3. Let's calculate the distance from the point characterizing the initial state to the center of gravity, $\mathrm{d}_{\mathrm{i} \text {-icg }}$, by the formula (21), putting in it the second coordinate $\mathrm{x}_{\mathrm{icg}}$. The calculation is carried out for each of the alternative lines of the final state.

Step 4. Choose one of the alternatives for which $\mathrm{d}_{\mathrm{i} \text {-icg }}=\mathrm{d}_{\mathrm{i} \text {-icg min }}$.

A demonstration of this principle is shown in Fig. 4. The obtained curves of the form $x_{1}=f\left(x_{2}\right)$ describe the set of suboptimal values of the input variables that provide the given values of the output variable (Fig. 2), i. e. they represent a multialternative description of the final state.

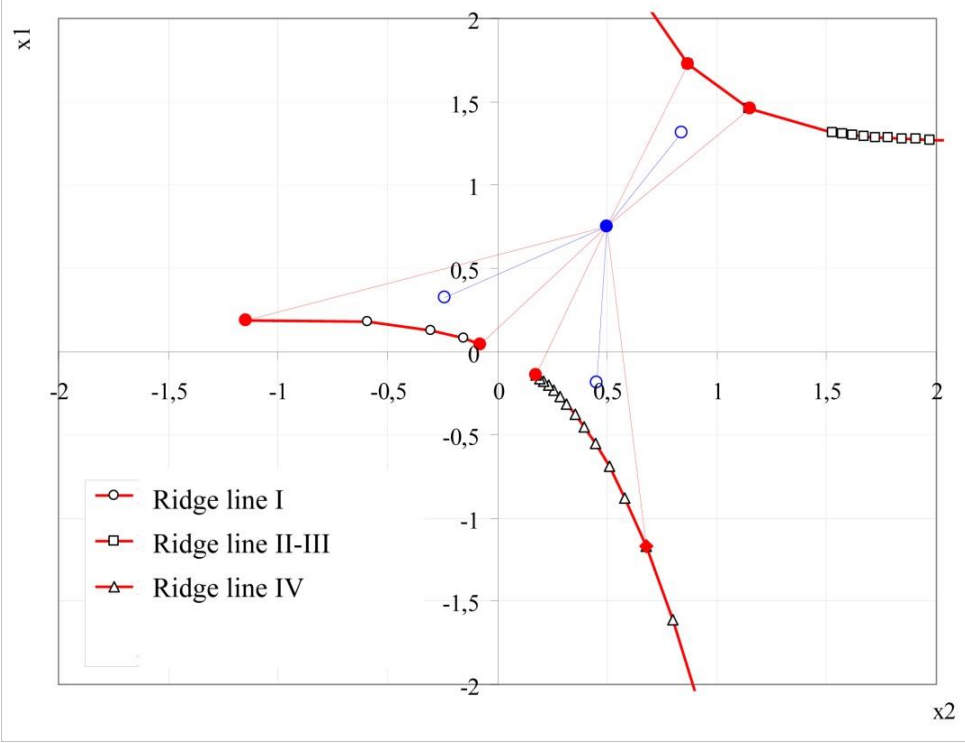

Fig. 4. The principle of a multialternative description of the final state and the principle of choosing the final state, with respect to which it is expedient to search for optimal control

In this sense, the proposed approach to the controller synthesis is universal, since it makes it possible to determine the control of the duplex induction melting process, which is optimal in the sense of stabilization for a given process parameter. The resulting solutions form the necessary logical conditions for the logic control unit (LCU) of the duplex process control system by induction melting, the basic structural diagram of which has the form shown in Fig. 5. 


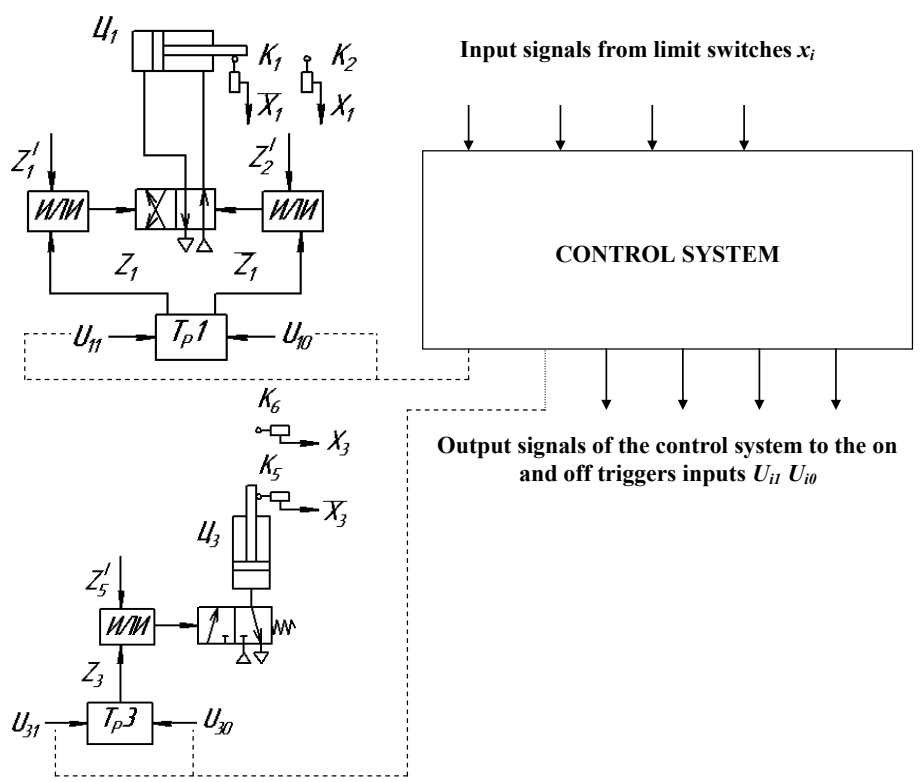

Fig. 5. General principle of the structural scheme of the control system for the duplex process of induction melting: $\mathrm{C}_{\mathrm{i}}$ - cylinders (actuators for moving the working bodies), $\mathrm{K}_{\mathrm{i}}-$ limit switches,

$\mathrm{Zi}$ - signals from the mode selection system (manual, adjustment, automatic), $\mathrm{T}_{\mathrm{p}} \mathrm{I}$ - triggers, input signals for storing the signal in non-fixed positions, $\mathrm{X}_{\mathrm{i}}$ - input signals taken from the limit switches, $\mathrm{U}_{\mathrm{i} 1}, \mathrm{U}_{\mathrm{i} 0}-$ signals coming to the on and off inputs of the trigger

\section{Discussion}

It should be noted that the choice of the optimal strategy in accordance with the proposed procedure can remove the uncertainty in the assessment of the input variables of the process if they are taken as indicators of the quality of the charge. It is this that can be considered an advantage of the proposed method of searching for melting control at the first stage of the duplex process.

Concerning the second stage of the duplex process, it should be noted that the description of the final state based on the solution of the ridge analysis problem can remove the uncertainty in the evaluation of the quality criterion for controlling the process of thermal treatment. Such uncertainty is connected with the possibility of a multialternative description of the final state that allows a lot of optimal solutions in terms of achieving a given quality. This is the advantage of the proposed approach in estimating the final state. It makes possible not only the synthesis of an optimal temperature control regulator based on the analysis of the CDE describing the control object, but also the application of the Pontryagin maximum principle to search for optimal control of the thermal treatment.

Disadvantages of the proposed methods for practical implementation are the costs associated with carrying out experimental industrial melting and the risks associated with obtaining negative results within the limits of budgets for carrying out industrial experiments. From the point of view of scientific results, the limitation of the model may be a disadvantage because of the influence on the output variable of only two factors - concerning the control of the second stage of the duplex process. Obtaining initial data for the search for an optimal control strategy for the first stage of the duplex process is also a weak point, because it is based on the limited amount of initial data, and on using expert opinion to estimate the likely costs when using different strategies.

\section{Conclusions}

1. The proposed procedure for finding the optimal control strategy for the melting step in the induction duplex process, based on the use of the theory of statistical games, makes it possible to remove the uncertainty in the estimation of the input variables of the process. 
2. The proposed procedure for a multialternative description of the final state, which allows a lot of optimal solutions in terms of achieving a given quality of cast iron, allows to remove uncertainty in the evaluation of the quality criterion for controlling the process of thermo-time treatment.

\section{References}

[1] Zinin, Yu. (2008). Predstavlenie nagruzki pri issledovanii skhemotekhnicheskih modeley tiristornyh preobrazovateley chastoty dlya indukcionnoy plavki metallov. Silovaya elektronika, 1, 73-84.

[2] Zlatin, I. (2007). Novye vozmozhnosti programmy skhemotekhnicheskogo modelirovaniya MicroCap. Komponenty i tekhnologii, 10, 34-46.

[3] Valiullina, Z., Zinin, Yu. (2007). Skhemotekhnicheskoe modelirovanie silovyh drosseley dlya tiristornyh preobrazovateley povyshennoy chastoty. Silovaya elektronika, 1, 93-99.

[4] Bolotovskiy, Yu. I., Gutin, L. I., Tanazly, G. I., SHulyak, A. A. (2005). Izmerenie parametrov induktorov ustanovok indukcionnogo nagreva na rezhimah, blizkih k nominal'nym. Silovaya elektronika, $1,78-80$.

[5] Zinin, Yu. M. (2006). Analiz intervala vosstanovleniya upravlyaemosti tiristora v nesimmetrichnom invertore. Elektrichestvo, 10, 54-62.

[6] Luzgin, V. I., Petrov, A. Yu., Fatkullin, S. M., Frizen, V. E. Indukcionnye plavil'no-liteynye kompleksy dlya proizvodstva vysokokachestvennogo chuguna. Available at: http://xn--jlaboj7cc.xn--plai/ upload/image/poslednya_statiya.pdf

[7] Kuvaldin, A. B., Fedin, M. A. Identifikaciya indukcionnyh tigel'nyh pechey i mikserov kak ob'ektov upravleniya i razrabotka parametricheskoy sistemy regulirovaniya temperatury rasplava. Available at: http://elcut.ru/publications/sbornik1/5kuvaldin.pdf

[8] Dymko, I., Muradian, A., Leheza, Y., Manzhula, A., Rudkovskyi, O. (2017). Integrated approach to the development of the effectiveness function of quality control of metal products. Eastern-European Journal of Enterprise Technologies, 6 (3 (90)), 26-34. doi: https://doi.org/10.15587/1729-4061.2017.119500

[9] Korshunov, Yu. M. (1980). Matematicheskie osnovy kibernetiki. Moscow: Energiya, 424.

[10] Demin, D. (2017). Synthesis of optimal control of technological processes based on a multialternative parametric description of the final state. Eastern-European Journal of Enterprise Technologies, 3 (4 (87)), 51-63. doi: https://doi.org/10.15587/1729-4061.2017.105294

[11] Vasenko, Yu. A. (2012). Technology for improved wear iron. Technology Audit and Production Reserves, 1 (1 (3)), 17-21. doi: https://doi.org/10.15587/2312-8372.2012.4870

[12] Raskin L. G., Demin, D. (2010). Iskusstvennaya ortogonalizaciya passivnogo eksperimenta v usloviyah maloy vyborki nechetkih dannyh. Informatsiyno-keruiuchi systemy na zaliznychnomu transporti, $1(80), 20-23$.

[13] Серая, O. B., Demin, D. (2010). Estimation of representative truncated orthogonal subplans of complete factor experiment plan. Systemni doslidzhennia ta informatsiyni tekhnolohiyi, 3, 84-88.

[14] Seraya, O. V., Demin, D. A. (2012). Linear Regression Analysis of a Small Sample of Fuzzy Input Data. Journal of Automation and Information Sciences, 44 (7), 34-48. doi: https://doi.org/10.1615/ jautomatinfscien.v44.i7.40 